University of Nebraska - Lincoln

DigitalCommons@University of Nebraska - Lincoln

Repeated Antipsychotic Treatment Progressively Potentiates Inhibition on Phencyclidine-Induced Hyperlocomotion, but Attenuates Inhibition on Amphetamine-Induced Hyperlocomotion: Relevance to Animal Models of Antipsychotic Drugs

Tao Sun

University of Nebraska- Lincoln, tsun2@unl.edu

Gang Hu

Nanjing Medical University

Ming Li

University of Nebraska-Lincoln, mli2@unl.edu

Follow this and additional works at: https://digitalcommons.unl.edu/psychfacpub

Part of the Psychiatry and Psychology Commons

Sun, Tao; Hu, Gang; and Li, Ming, "Repeated Antipsychotic Treatment Progressively Potentiates Inhibition on Phencyclidine-Induced Hyperlocomotion, but Attenuates Inhibition on Amphetamine-Induced Hyperlocomotion: Relevance to Animal Models of Antipsychotic Drugs" (2009). Faculty Publications, Department of Psychology. 411.

https://digitalcommons.unl.edu/psychfacpub/411

This Article is brought to you for free and open access by the Psychology, Department of at DigitalCommons@University of Nebraska - Lincoln. It has been accepted for inclusion in Faculty Publications, Department of Psychology by an authorized administrator of DigitalCommons@University of Nebraska - Lincoln. 


\title{
Repeated Antipsychotic Treatment Progressively Potentiates Inhibition on Phencyclidine-Induced Hyperlocomotion, but Attenuates Inhibition on Amphetamine-Induced Hyperlocomotion: Relevance to Animal Models of Antipsychotic Drugs
}

\author{
Tao Sun ${ }^{\mathrm{a}, \mathrm{b}}$, Gang $\mathrm{Hu}^{\mathrm{a}}$, Ming $\mathrm{Li}^{\mathrm{b}, *}$ \\ a Jiangsu Key Laboratory of Neurodegeneration, Department of Pharmacology, Nanjing Medical University, China \\ ${ }^{\mathrm{b}}$ Department of Psychology, University of Nebraska-Lincoln, Lincoln, Nebraska, USA \\ *mli2@unl.edu
}

Received October 22, 2008; received in revised form November 3, 2008; accepted November 20, 2008; available online November 27, 2008.

Keywords: Amphetamine; Phencyclidine; Antipsychotic drug; Anxiolytic drug; Hyperlocomotor activity; Schizophrenia; Animal models of schizophrenia.

\begin{abstract}
Clinical obervations indicate that antipsychotic action starts early and increases in magnitude with repeated treatment. Animal models that faithfully capture this time course of action are few. Inhibition of hyperlocomotion induced by amphetamine or phencyclidine has been widely used as a screening tool for the antipsychotic activity of a drug. We thus investigated whether repeated antipsychotic treatment could produce an early-onset and progressively increased antagonistic effect on amphetamine or phencyclidine-induced hyperlocomotion as a way of assessing the validity of such models in capturing time course of antipsychotic action. One each of the five consecutive test days, different groups of rats $(n=6-7 /$ group) received an initial injection of either haloperidol (0.01-0.10 mg/kg, sc), clozapine (5-20.0 mg/ kg, sc), olanzapine (1.0 mg/ kg, sc), chlordiazepoxide (10.0 mg/ $\mathrm{kg}$, ip) or vehicle (sterile water, sc) $30 \mathrm{~min}$ prior to a second injection of either amphetamine (1.5 mg/ $\mathrm{kg}$, sc) or phencyclidine (3.2 $\mathrm{mg} / \mathrm{kg}$, sc). Motor activity was subsequently monitored for $60 \mathrm{~min}$ after amphetamine or phencyclidine treatment. Repeated treatment of haloperidol, clozapine, or olanzapine progressively potentiated inhibition on repeated phencyclidine-induced hyperlocomotion and prolonged this action over the five consecutive days. In contrast, antipsychotic inhibition on repeated amphetamine-induced hyperlocomotion was gradually attenuated and shortened. Repeated treatment of chlordiazepoxide, a benzodiazepine anxiolytic, retained its inhibition on amphetamine-induced hyperlocomotion, but had no effect on phencyclidine-induced one. These results suggest that repeated phencyclidine-induced hyperlocomotion model based on repeated antipsychotic treatment regimen is capable of capturing the progressive increase pattern of antipychotic treatment seen in the clinic and differentiating antipsychotics from anxiolytics; thus it may serve as a better model for the investigation of the neurobiological mechanisms of action of antipsychotic drugs and delineating the pathophysiology of schizophrenia.
\end{abstract}

\section{Introduction}

Recent years have witnessed a growing number of clinical studies suggesting that antipsychotic action starts early and increases in magnitude with repeated treatment (Agid et al., 2003, 2006; Emsley et al., 2006; Glick et al., 2006; Kapur et al., 2005; Leucht et al., 2005; Raedler et al., 2007). For example, Agid et al. (2003) examined 42 double-blind, comparator-controlled studies (> 7000 patients) using a meta-analysis technique. They found that psychotic symptoms improved within the first week of treatment and showed a progressive improvement over subsequent weeks, with the overall pattern of improvement approximating an exponential curve. Leucht et al. (2005) analyzed a large homogeneous database of original patient data from 7 random- ized, double-blind studies of the efficacy of amisulpride in patients with schizophrenia spectrum disorders and found the same results. More improvement occurs in the first few days than in any later period of equal duration (Leucht et al., 2005). These findings are in contrast to the traditional held belief that the onset of antipsychotic action is delayed and takes 2-3 weeks before the onset of therapeutic benefits is produced (Gelder et al., 2000).

This change in our clinical understanding demands a re-examination of the currently available animal models of antipsychotic drugs. Many models rely on the acute effects of antipsychotic treatment, including amphetamine-induced hyperlocomotion, the catalepsy and paw test to prepulse inhibition, latent inhibition, and social interaction (Arnt, 1982; Ellenbroek et al., 1987; Hoffman and 
Donovan, 1995; Sams-Dodd, 1999; Swerdlow et al., 2000; Weiner, 2003). Because of the limitation of acute treatment regimen, none of these models provides a relevant model of time course of antipsychotic effect. On the other hand, models that have used chronic treatment regimens, such as "depolarization block" (Grace and Bunney, 1986), antipsychotic-induced Fos expression (Robertson and Fibiger, 1992), social behavior (Sams-Dodd, 1998), or the chronic prepulse inhibition model (Andersen and Pouzet, 2001), have often examined behavioral or physiological changes after a certain period of treatment has elapsed (e.g., $\sim 21$ days after the first drug administration), instead of during the chronic treatment period. Thus, they are limited in tracking changes that occur during the treatment period.

We recently developed a rat conditioned avoidance responding model based on a repeated treatment regimen and examined its validity in modeling the time course of antipsychotic effect ( $\mathrm{Li}$ et al., 2007). We found that rats repeatedly treated with haloperidol, olanzapine, or risperidone exhibited a decrease in avoidance responding starting on the first day of treatment. Over the seven daily test sessions, their avoidance responding displayed a progressive, acrosssession decline, which recovered after treatment was stopped. In contrast, rats treated with chlordiazepoxide or vehicle maintained a high level of avoidance responding throughout the entire testing period. Thus the repeated treatment conditioned avoidance responding model seems capable of mimicking several key features of clinical effects of antipsychotics, such as early-onset, progressive accumulation, asymptote, and drug-discontinuation relapse.

The present study represents another attempt to develop clinically relevant animal models of antipsychotic activity that capture important hallmarks of clinical features of antipsychotic treatment along the time course of antipsychotic treatment in the clinic. The objective was to investigate whether repeated antipsychotic treatment, as opposed to anxiolytic treatment, could produce an early-onset and progressively increased inhibitory effect on the amphetamine or phencyclidine-induced hyperlocomotion. Both amphetamine and phencyclidine-induced hyperlocomotion models are commonly used as screening tools for the detection of antipsychotic activity. When given acutely, all antipsychotics inhibit hyperlocomotor activity induced by acute administrations of amphetamine or phencyclidine (Arnt, 1995; Gleason and Shannon, 1997). However, little is known about the effects of repeated antipsychotic treatment on the motor activity induced by repeated amphetamine or phencyclidine treatment.

\section{Materials and methods}

\subsection{Animals}

A total of 144 male Sprague-Dawley rats (226-250 g upon arrival, Charles River, Portage, MI) were used. They were housed two per cage, in $48.3 \mathrm{~cm} \times 26.7 \mathrm{~cm} \times 20.3 \mathrm{~cm}$ transparent polycarbonate cages under 12-h light/dark conditions (light on between 6:30 am and $6: 30 \mathrm{pm})$. Room temperature was maintained at $21 \pm 1^{\circ} \mathrm{C}$ with a relative humidity of $55-60 \%$. Food and water were available ad libitum. Animals were allowed at least one week of habituation to the animal facility before being used in experiments. All procedures were approved by the Institutional Animal Care and Use Committee at the University of Nebraska-Lincoln.

\subsection{Drugs}

The injection solutions of haloperidol $(5 \mathrm{mg} / \mathrm{ml}$ ampoules, Sabex Inc. Boucheville, Quebec, Canada) and chlordiazepoxide (SigmaAldrich, St. Louis, MO) were obtained by mixing drugs with sterile water. The injection solutions of d-amphetamine sulfate (Sigma-RBI) and phencyclidine hydrochloride (gift from National Institute on Drug Abuse Chemical Synthesis and Drug Supply Program) were obtained by mixing drugs with $0.9 \%$ saline. Clozapine (gift from the NIMH drug supply program) and olanzapine (Toronto Research Chemical Inc., Canada) were dissolved in $1.5 \%$ glacial acetic acid dis- tilled water. Haloperidol, clozapine, olanzapine, amphetamine and phencyclidine were administered subcutaneously, whereas chlordiazepoxide was administered intraperitoneally.

\subsection{Locomotor activity apparatus}

Sixteen activity boxes were housed in a quiet room. The boxes were $48.3 \mathrm{~cm} \times 26.7 \mathrm{~cm} \times 20.3 \mathrm{~cm}$ transparent polycarbonate cages, which were similar to the home cages but were each equipped with a row of 6 photocell beams ( $7.8 \mathrm{~cm}$ between two adjacent photobeams) placed $3.2 \mathrm{~cm}$ above the floor of the cage. A computer detected the disruption of the photocell beams and recorded the number of beam breaks. All experiments were run during the light cycle.

\subsection{Experiment 1: effects of repeated haloperidol and clozapine treatment on amphetamine-induced hyperlocomotion}

In this experiment, we examined the effects of repeated haloperidol and clozapine treatment on amphetamine-induced hyperlocomotion. We chose three doses of haloperidol $(0.01,0.05$ and $0.10 \mathrm{mg} /$ $\mathrm{kg}$ ) and clozapine $(5,10$, and $20 \mathrm{mg} / \mathrm{kg}$ ) which cover subclinical, optimal clinical, and supra-clinical doses based on the dopamine $\mathrm{D}_{2}$ occupancy data ( $50 \%-75 \%$ occupancy) (Kapur et al., 2003a). Also, at the medium and high doses, both haloperidol and clozapine selectively disrupt avoidance responding - a validated behavioral index of antipsychotic activity ( $\mathrm{Li}$ et al., 2004). The dose for amphetamine was $1.5 \mathrm{mg} / \mathrm{kg}$, which is the common dose used in the literature (Arnt, 1995; Natesan et al., 2006; Sills et al., 2000).

\subsection{Experimental procedure}

Forty-eight rats were randomly assigned to one of eight groups ( $n$ = 6/group): vehicle (water) + vehicle (saline, SAL), vehicle (water) + amphetamine, haloperidol $(0.01 \mathrm{mg} / \mathrm{kg})+$ amphetamine, haloperidol $(0.05 \mathrm{mg} / \mathrm{kg})+$ amphetamine, haloperidol $(0.10 \mathrm{mg} / \mathrm{kg})$ + amphetamine, clozapine $(5.0 \mathrm{mg} / \mathrm{kg})+$ amphetamine, clozapine $(10.0 \mathrm{mg} / \mathrm{kg})+$ amphetamine, and clozapine $(20.0 \mathrm{mg} / \mathrm{kg})+$ amphetamine. After two days of habituation to the testing room and the testing boxes (30 $\mathrm{min} /$ day for 2 days), on day 1, rats first received one of the following seven subcutaneous injections: vehicle (sterile water), haloperidol $0.01,0.05$, or $0.10 \mathrm{mg} / \mathrm{kg}$, or clozapine $5.0,10.0$, or $20.0 \mathrm{mg} / \mathrm{kg}$. They were then immediately placed in locomotor activity boxes for $30 \mathrm{~min}$. At the end of the 30-min period, rats were taken out and injected with either vehicle (sc) or amphetamine $(1.5 \mathrm{mg} / \mathrm{kg}$, sc) and placed back in the boxes for another $60 \mathrm{~min}$. Locomotor activity (number of photobeam breaks) was measured in 5 min intervals throughout the entire 90-min testing session. This procedure was repeated for another 4 days (a total of 5 testing days).

\subsection{Experiment 2: effects of repeated haloperidol and clozapine treatment on phencyclidine-induced hyperlocomotion}

Experiment 2 examined the effects of repeated haloperidol and clozapine treatment on phencyclidine-induced hyperlocomotion. The basic procedure was identical to that of Experiment 1 with the exception that phencyclidine $(3.2 \mathrm{mg} / \mathrm{kg}$, sc) was used. This dose of phencyclidine is shown to induce a robust hyperlocomotion effect without causing severe stereotypy (Gleason and Shannon, 1997; Kalinichev et al., 2008).

2.7. Experiment 3: effects of repeated olanzapine and chlordiazepoxide treatment on amphetamine or phencyclidine-induced hyperlocomotion

Experiment 3 examined the effects of repeated olanzapine and chlordiazepoxide treatment on amphetamine or phencyclidine induced hyperlocomotion. Forty-eight rats were randomly assigned to one of seven groups ( $n=6 /$ vehicle group, $n=7$ for other groups): vehicle (water, sc or ip) + vehicle (saline, sc), vehicle (water, sc) + 
amphetamine $(1.5 \mathrm{mg} / \mathrm{kg}$, sc), vehicle (water, sc) + phencyclidine (3.2 mg/ kg, sc), olanzapine (1.0 mg/ kg, sc) + amphetamine, olanzapine $(1.0 \mathrm{mg} / \mathrm{kg}, \mathrm{sc})+$ phencyclidine, chlordiazepoxide $(10.0 \mathrm{mg} / \mathrm{kg}$, ip) + amphetamine, and chlordiazepoxide $(10.0 \mathrm{mg} / \mathrm{kg}$, ip) + phencyclidine. The basic procedure was identical to that of Experiment 1. We chose olanzapine $1.0 \mathrm{mg} / \mathrm{kg}$ dose because this is a clinically relevant dose in terms of its ability to disrupt conditioned avoidance responding ( $\mathrm{Li}$ et al., 2007), as well as to give rise to $\sim 70 \%$ striatal $\mathrm{D}_{2}$ occupancy (Kapur et al., 2003b). We included $10.0 \mathrm{mg} / \mathrm{kg}$ chlordiazepoxide as a pharmacological control. This dose of chlordiazepoxide is ineffective in disrupting avoidance responding (Li et al., 2004, 2007; Mead et al., 2008), but it is effective in several aversively conditioned paradigms, such as Pavlovian fear conditioning and passive avoidance responding (Burghardt et al., 2004; Joordens et al., 1998; Klint, 1991; Mead et al., 2008).

\subsection{Statistical analysis}

Motor activity data from the five consecutive drug test days were expressed as mean values \pm S.E.M. and analyzed using a factorial repeated measures ANOVA with the between-subjects factor being the treatment conditions ("Treatment," e.g. 3 doses of haloperidol vs. vehicle), and the within-subject factor being the test days ("Days," e.g. day 1 test, day 2 test, etc.), followed by Post-hoc Tukey tests to examine two-group difference. Motor activity data from each daily test were also analyzed using a factorial repeated measures ANOVA with the between-subjects factor being the treatment conditions ("Treatment," e.g. 3 doses of haloperidol vs. vehicle), and the within-subject factor being the 5-min time block ("Block," e.g. block for $60 \mathrm{~min}$ after amphetamine or phencyclidine injection). If necessary, one-way ANOVA was used to identify two-group difference. A conventional two-tailed level of significance at the $5 \%$ level was required.

\section{Results}

3.1. Experiment 1: effects of repeated haloperidol and clozapine treatment on amphetamine-induced hyperlocomotion

3.1.1. Acute haloperidol and clozapine treatment dose-dependently inhibited the hyperlocomotion induced by amphetamine

Figure 1 shows the mean locomotor activity of the eight groups of rats during the 60 -min test period after vehicle or amphetamine injection across the five test days. On day 1, acute haloperidol and clozapine treatment dose-dependently inhibited the hyperlocomotion induced by amphetamine. One-way ANOVA revealed that there was a significant main effect of "Treatment" $\left(F_{(7,47)}=16.368, P<\right.$ 0.001). Post-hoc Tukey tests showed that in comparison to the vehicle treatment, amphetamine produced a robust increase in motor activity $(P<0.001)$. This amphetamine effect was significantly attenuated by haloperidol at $0.05 \mathrm{mg} / \mathrm{kg}(P=0.006)$ and $0.10 \mathrm{mg} / \mathrm{kg}(P<$ $0.001)$ and clozapine at 10.0 and $20.0 \mathrm{mg} / \mathrm{kg}(P<0.001)$. Low dose of haloperidol $(0.01 \mathrm{mg} / \mathrm{kg})$ and clozapine $(5.0 \mathrm{mg} / \mathrm{kg})$ did not significantly inhibit amphetamine-induced hyperlocomotion (haloperidol $0.01 \mathrm{mg} / \mathrm{kg}, P=0.999$; clozapine $5.0 \mathrm{mg} / \mathrm{kg}, P<0.148$ vs. the vehicle + amphetamine group).

3.1.2. Repeated haloperidol and clozapine treatment attenuated the inhibition on the amphetamine-induced hyperlocomotion across days

Two-way repeated measures ANOVA with the treatment conditions as the between-subjects variable and testing days as the withinsubjects variable revealed a significant main effect of "Treatment" $(\mathrm{F}(7,40)=13.074, \mathrm{P}<0.001)$, a significant main effect of "Days" $\left(F_{(4,160)}\right.$ $=16.701, P<0.001)$, and "Treatment" $\times$ "Days" interaction $\left(F_{(28,160)}=\right.$ $1.965, P=0.005)$. This interaction effect was attributed to the acrosssession change in the effects of repeated haloperidol and clozapine treatments on amphetamine-induced hyperlocomotion. Over the 5 test days, repeated amphetamine treatment did not significantly increase motor activity $\left(F_{(4,20)}=1.513, P=0.236\right)$. However, five out of six antipsychotic-treated groups showed a significant upward increase in motor activity (all $P \mathrm{~s}<0.05$, except the haloperidol 0.01 $\mathrm{mg} / \mathrm{kg}$ group, $\left.F_{(4,20)}=1.707, P=0.188\right)$, indicating that the inhibitory effect of haloperidol and clozapine was gradually weakened by repeated drug administration.

This attenuation effect was most apparent with the highest dose of haloperidol $(0.10 \mathrm{mg} / \mathrm{kg})$ and clozapine $(20 \mathrm{mg} / \mathrm{kg})$ (see Figure 1). For example, haloperidol at $0.10 \mathrm{mg} / \mathrm{kg}$ reduced amphetamineinduced hyperlocomotion by $77 \%$ on day 1 , but only $54 \%$ on day 5 . Similarly, clozapine at $20.0 \mathrm{mg} / \mathrm{kg}$ reduced amphetamine-induced hyperlocomotion by $64 \%$ on day 1 , but only $31 \%$ on day 5 . Percent inhibition was calculated using this formula:

$\%$ inhibition $=1-\frac{\text { Motor activity of one of the drug groups }}{\text { Motor activity of the vehicle }+ \text { amphetamine group }}$

3.1.3. Repeated haloperidol and clozapine treatment shortened the time course of the inhibitory action on amphetamine-induced hyperlocomotion

Figure 2 shows the time course (measured in 5-min blocks over the 60-min period after amphetamine injection) of the effects of haloperidol and clozapine treatment on amphetamine-induced hyperlo-
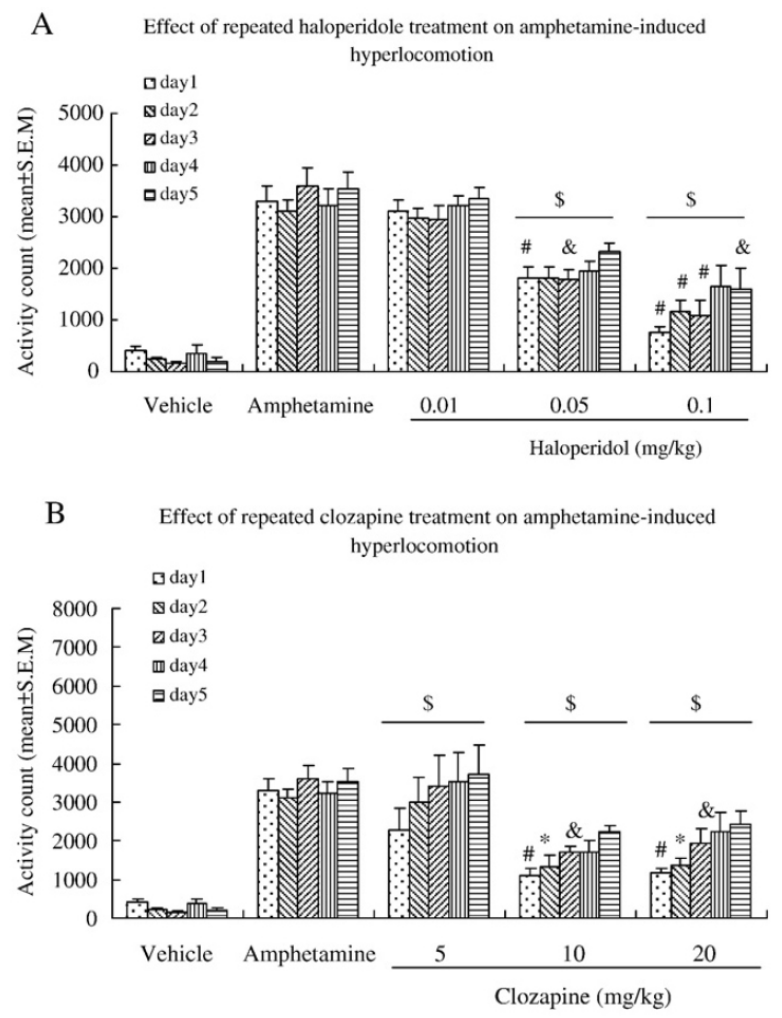

Fig. 1. Effect of repeated haloperidol $(0.01,0.05$ or $0.1 \mathrm{mg} / \mathrm{kg})(\mathrm{A})$ or clozapine $(5.0,10.0$ or $20.0 \mathrm{mg} / \mathrm{kg}$ ) (B) treatment on hyperlocomotion induced by amphetamine on the five test days ( $n=6 /$ group). Locomotor activity was measured for $60 \mathrm{~min}$ after vehicle or amphetamine injection and expressed as Mean \pm S.E.M for each group. Data analyses were done by using one-way ANOVA (for day 1 data: "Treatment") and two-way repeated measures ANOVAs ("Treatment" “"Days" for days 1 to 5 data) followed by Post-hoc Tukey tests. ${ }^{\circledR} P<0.05,{ }^{*} P<0.01,{ }^{\#} P<0.001$, indicate levels of significance relative to the vehicle + amphetamine group. ${ }^{S} P<0.05$, indicate significant difference across the 5 test days within each group. 
A



B

Day 5 Haloperidol Treatment



Day 1 Clozapine Treatment

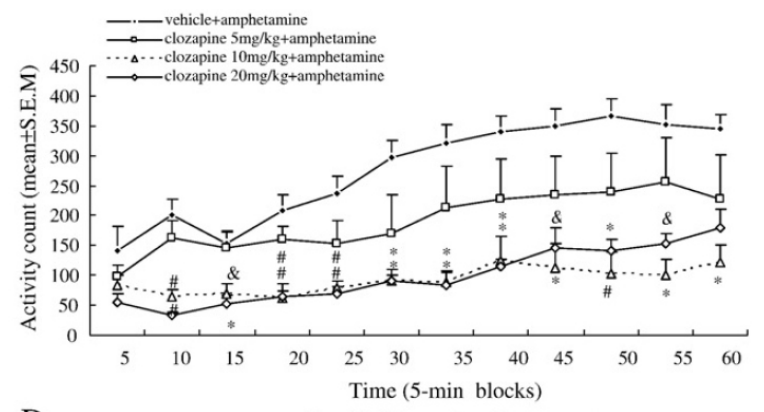

$\mathrm{D}$

Day 5 Clozapine Treatment



Fig. 2. Time course effect of haloperidol $(0.01,0.05$ or $0.1 \mathrm{mg} / \mathrm{kg}$ ) (A and B) and clozapine (5.0, 10.0 or $20.0 \mathrm{mg} / \mathrm{kg}$ ) (C and D) on amphetamine-induced hyperlocomotion on day 1 and day 5 . Locomotor activity was measured over 125 -min blocks and expressed as Mean \pm S.E.M. Data for day 1 and day 5 were analyzed separately by using two-way repeated measures ANOVA ("Treatment" $\times$ "Block") followed by Post-hoc Tukey tests. ${ }^{\circledR} P<0.05,{ }^{*} P<0.01,{ }^{\#} P<0.001$, indicate levels of significance relative to the vehicle+amphetamine group.

comotion on the first and last day of drug testing (excluding the vehicle + vehicle group). It appears that with repeated treatment, haloperidol and clozapine shortened its inhibition on amphetamineinduced hyperlocomotion. For example, on day 1, the inhibitory effect of haloperidol $0.10 \mathrm{mg} / \mathrm{kg}$ started at the 10-min point after the amphetamine injection and lasted for the remainder of the test session (all $P_{\mathrm{s}}<0.001$ in comparison to the vehicle + amphetamine group). However, on day 5 , although its inhibitory effect also started at the 10 -min point $(P=0.001)$, the inhibition only lasted about 40 $\mathrm{min}$ as the haloperidol $0.10 \mathrm{mg} / \mathrm{kg}$ group no longer differed significantly from the vehicle + amphetamine group on the last two 5-min blocks (all Ps < 0.05). Similarly for clozapine, on day 1, clozapine 10 $\mathrm{mg} / \mathrm{kg}$ and $20 \mathrm{mg} / \mathrm{kg}$ inhibited amphetamine-induced hyperlocomotion starting at the 10-min point (all $P_{\mathrm{S}}<0.001$ ) and lasted for the remainder of the test session (all $P_{\mathrm{S}}<0.04$ one-tailed in comparison to the vehicle + amphetamine group). In contrast, on day 5 , the two clozapine groups did not differ significantly from the vehicle + amphetamine group in any 5-min blocks except one (all $P_{\mathrm{s}}<0.05$ except at the 45 -min point, $P=0.03$ for clozapine $10 \mathrm{mg} / \mathrm{kg}$ group vs. the vehicle + amphetamine).

\subsection{Experiment 2: effects of repeated haloperidol and clozapine treatment on phencyclidine-induced hyperlocomotion}

3.2.1. Acute haloperidol and clozapine treatment dose-dependently inhibited the hyperlocomotion induced by phencyclidine

Figure 3 shows the mean locomotor activity of the eight groups of rats during the 60 -min period after vehicle or phencyclidine injection across the five test days. On day 1 , acute haloperidol and clozapine treatment dose-dependently inhibited phencyclidine-induced hyperlocomotion. One-way ANOVA revealed that there was a significant main effect of "Treatment" $\left(F_{(7,47)}=27.203, P<0.001\right)$. Posthoc Tukey tests showed that in comparison to the vehicle treatment,

A Effects of repeated haloperidol treatment on phencyclidine-induced

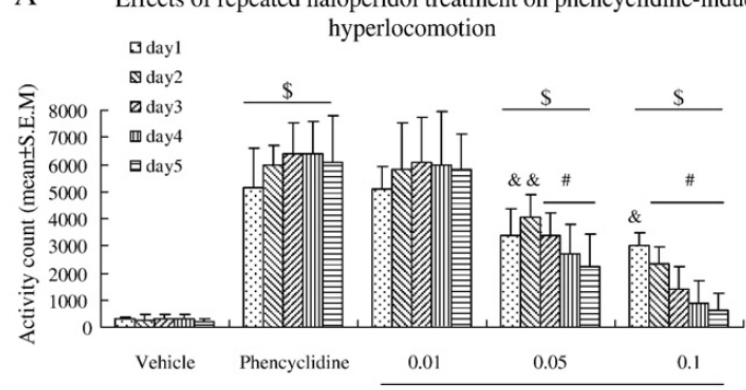

Haloperidol (mg/kg)

B Effects of repeated clozapine treatment on phencyclidine-induced hyperlocomotion

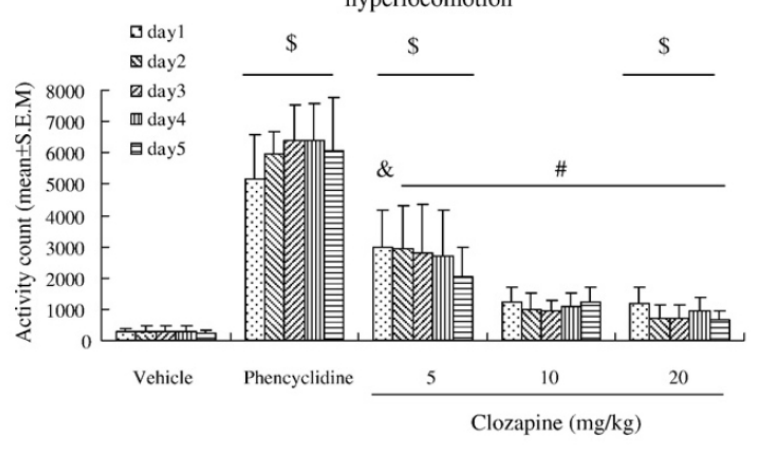

Fig. 3. Effect of repeated haloperidol $(0.01,0.05$ or $0.10 \mathrm{mg} / \mathrm{kg}$ ) (A) or clozapine $(5.0,10.0$ or $20.0 \mathrm{mg} / \mathrm{kg}$ ) (B) treatment on hyperlocomotion induced by phencyclidine over the five test days ( $n=6 /$ group). Locomotor activity was measured for $60 \mathrm{~min}$ after vehicle or phencyclidine injection and expressed as Mean \pm S.E.M for each group. Data analyses were done by using one-way ANOVA (for day 1 data: "Treatment") and two-way repeated measures ANOVAs ("Treatment" $\times$ "Days" for days 1 to 5 data) followed by Post-hoc Tukey tests. ${ }^{\circledR} P<0.05,{ }^{*} P<0.01,{ }^{\#} P<0.001$, indicate levels of significance relative to the vehicle+ phencyclidine group. ${ }^{5} P<0.05$, indicate significant difference across the 5 test days within each group. 
phencyclidine produced a robust increase in motor activity $(P<$ $0.001)$. This phencyclidine effect was significantly attenuated by haloperidol at $0.05 \mathrm{mg} / \mathrm{kg}(P=0.016)$ and $0.10 \mathrm{mg} / \mathrm{kg}(P=0.002)$ and clozapine at all three doses (all $\left.P_{\mathrm{s}}<0.002\right)$. Low dose of haloperidol $(0.01 \mathrm{mg} / \mathrm{kg})$ did not significantly inhibit phencyclidineinduced hyperlocomotion (haloperidol $0.01 \mathrm{mg} / \mathrm{kg}, P=1.00$ ).

3.2.2. Repeated haloperidol and clozapine treatment potentiated the inhibition on phencyclidine-induced hyperlocomotion across days

Two-way repeated measures ANOVA with treatment conditions as the between-subjects variable and test days as the within-subjects variable revealed a significant main effect of "Treatment" $\left(F_{(740)}=\right.$ $44.577, P<0.001)$, a significant main effect of "Days" $\left(F_{(4,160)}=5.079\right.$, $P=0.001)$, and "Treatment" $\times$ "Days" interaction $\left(F_{(28,160)}=4.035, P\right.$ $<0.001)$. This interaction effect was attributed to the across-session change in the effects of repeated haloperidol and clozapine treatment on phencyclidine-induced hyperlocomotion. Throughout the 5 test days, repeated phencyclidine treatment significantly increased motor activity $\left(F_{(4,20)}=4.080, P=0.014\right)$, indicating a phencyclidineinduced behavioral sensitization. Despite this, repeated treatment of haloperIdol and clozapine progressively strengthened their ability to inhibit phencyclidine-induced hyperlocomotion. Across the 5 drug test days, four out of six antipsychotic-treated groups showed a significant decrease in motor activity (all $P_{\mathrm{S}}<0.05$, except the haloperidol $0.01 \mathrm{mg} / \mathrm{kg}$ group, $F_{(4,20)}=0.804, P=0.537$ and clozapine 10 $\mathrm{mg} / \mathrm{kg}$ group, $\left.F_{(4,20)}=0.523, \stackrel{P}{P}=0.720\right)$. This potentiated inhibition was most apparent in the haloperidol $0.10 \mathrm{mg} / \mathrm{kg}$ group and clozapine $5.0 \mathrm{mg} / \mathrm{kg}$ group. For example, haloperidol at $0.10 \mathrm{mg} / \mathrm{kg}$ reduced phencyclidine-induced hyperlocomotion by $42 \%$ on day 1 , but $89 \%$ on day 5 . Similarly, clozapine at $5.0 \mathrm{mg} / \mathrm{kg}$ reduced phencyclidine-induced hyperlocomotion by $42 \%$ on day 1 , but up to $66 \%$ on day 5 .

3.2.3. Repeated haloperidol and clozapine treatment prolonged the time course of the inhibitory action on phencyclidine-induced hyperlocomotion

Figure 4 shows the time course (measured in 5-min blocks for the 60-min period after phencyclidine injection) of the effects of haloperidol and clozapine treatment on phencyclidine-induced hyperlocomotion on the first and last day of drug testing (excluding the vehicle + vehicle group). It appears that with repeated treatment, haloperidol and clozapine advanced or prolonged their inhibition on phencyclidine-induced hyperlocomotion. For example, on day 1 , the inhibitory effect of haloperidol $0.10 \mathrm{mg} / \mathrm{kg}$ started at the 20-min point after the phencyclidine injection, and lasted for the remainder of the test session (all $P \mathrm{~s}<0.05$ in comparison to the vehicle + phencyclidine group except at the 25 -min point $P s<0.05$ ). On day 5 , its inhibitory effect started at the 10 -min point $(P=0.008)$, and lasted for the remainder of the test session (all $P \mathrm{~s}<0.001$ in comparison to the vehicle + phencyclidine group except at the 10 -min point $P=0.008$ ). Similarly for clozapine, on day 1 , clozapine $5.0 \mathrm{mg} / \mathrm{kg}$ inhibited the phencyclidine-induced hyperlocomotion starting at the 20-min point $(P<0.05)$, and lasted for the remainder of the test session (all $P \mathrm{~s}<0.05)$. On day 5 , clozapine $5 \mathrm{mg} / \mathrm{kg}$ inhibited the phencyclidineinduced hyperlocomotion starting at the 10 -min point, and lasted for the remainder of the test session (all $P_{\mathrm{s}}<0.001$ ).

3.3. Experiment 3: effects of repeated olanzapine and chlordiazepoxide treatment on amphetamine or phencyclidine-induced hyperlocomotion

3.3.1. Acute olanzapine and chlordiazepoxide treatment inhibited the hyperlocomotion induced by amphetamine, but only olanzapine inhibited the hyperlocomotion induced by phencyclidine

Figure 5 shows the mean locomotor activity of the seven groups of rats during the 60 -min period after amphetamine (Figure $5 \mathrm{~A}$ ) or phencyclidine (Figure 5B) injection across the five test days. On day 1 , one-way ANOVA analysis revealed a significant main effect of "Treatment" $\left(F_{(2,20)}=12.237, P<0.001\right)$. Post-hoc Tukey tests showed
A Day 1 Haloperidol Treatment

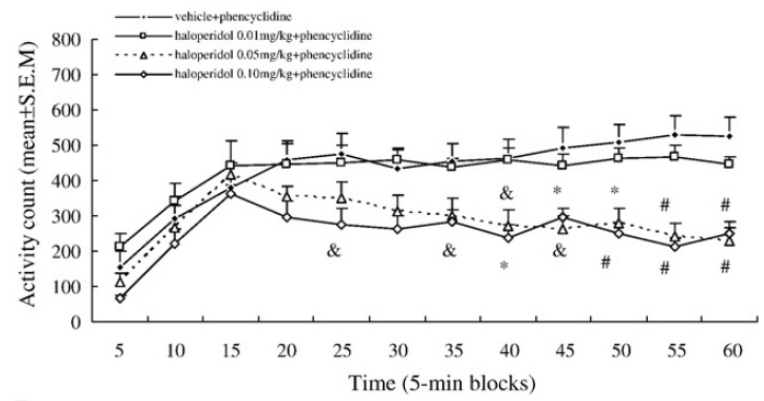

B

Day 5 Haloperidol Treatment

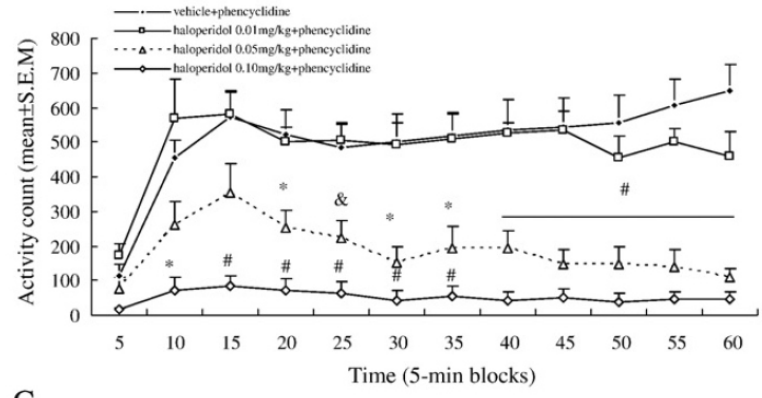

C

Day 1 Clozapine Treatment

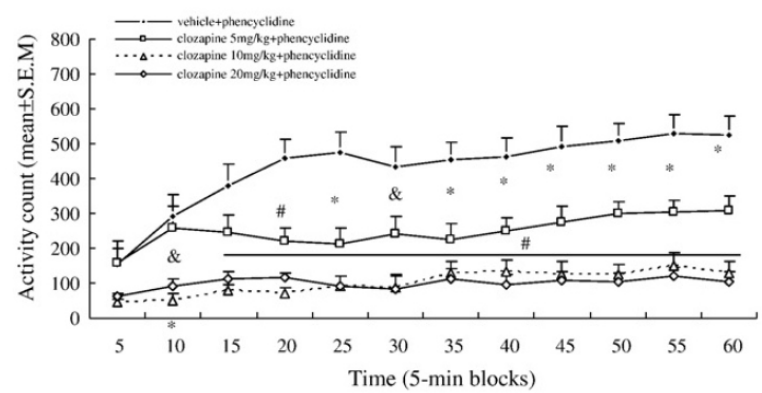

D

Day 5 Clozapine Treatment

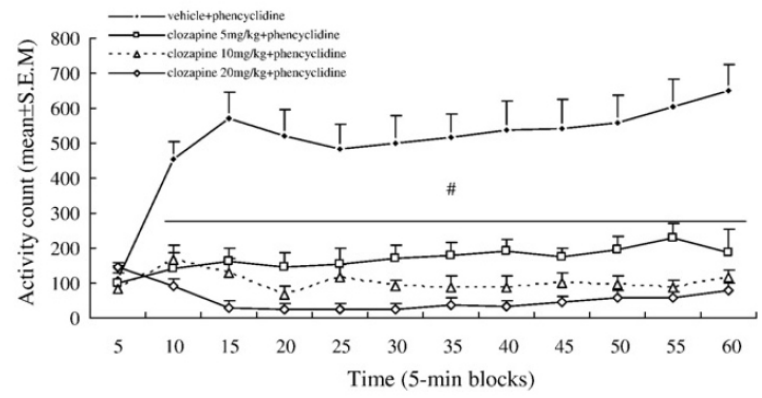

Fig. 4. Time course effect of haloperidol $(0.01,0.05$ or $0.1 \mathrm{mg} / \mathrm{kg}$ ) (A and B) or clozapine $(5.0,10.0$ or $20.0 \mathrm{mg} / \mathrm{kg}$ ) ( $C$ and $\mathrm{D})$ on hyperlocomotion induced by phencyclidine on test day 1 and day 5 . Locomotor activity was measured over 125 -min blocks and expressed as Mean \pm S.E.M. Data for day 1 and day 5 were analyzed separately by using two-way repeated measures ANOVA ("Treatment"x “Block") followed by Post-hoc Tukey tests. ${ }^{8} P<0.05,{ }^{*} P<0.01,{ }^{\#} P<0.001$, indicate levels of significance relative to the vehicle + phencyclidine group.

that in comparison to the vehicle treatment, amphetamine produced a robust increase in motor activity $(P<0.001)$. Olanzapine at $1.0 \mathrm{mg} /$ $\mathrm{kg}$ and chlordiazepoxide at $10.0 \mathrm{mg} / \mathrm{kg}$ significantly inhibited the 
A Effect of repeated olanzapine or chlordiazepoxide treatment on amphetamine-induced hyperlocomotion

Odayl

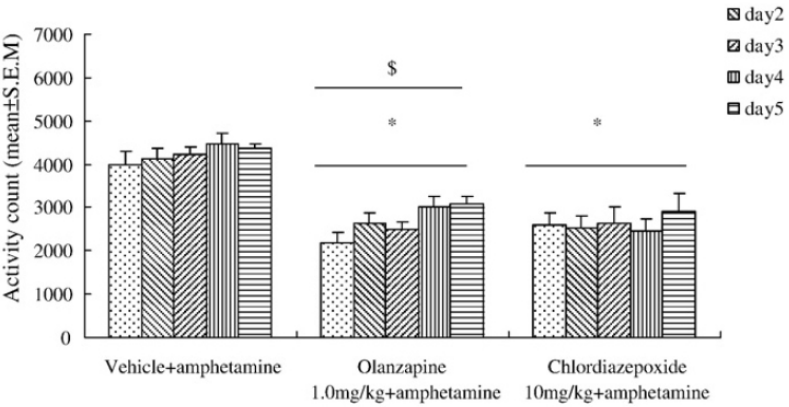

B Effect of repeated olanzapine or chlordiazepoxide treatment on

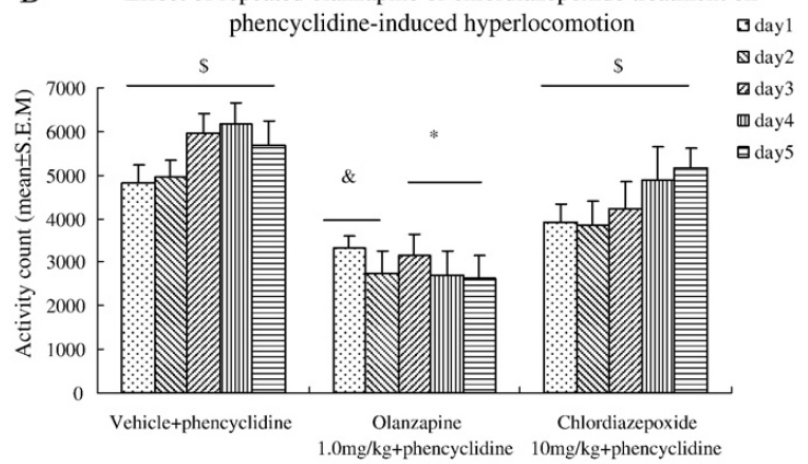

Fig. 5. Effect of repeated olanzapine $(1.0 \mathrm{mg} / \mathrm{kg})$ or chlordiazepoxide $(10.0 \mathrm{mg} / \mathrm{kg})$ treatment on the hyperlocomotion induced by amphetamine (A) or phencyclidine (B) for the five test days ( $n=6 /$ group). Locomotor activity was measured for $60 \mathrm{~min}$ after vehicle, amphetamine or phencyclidine injection and expressed as Mean \pm S.E.M. Data analyses were done by using one-way ANOVA (for day 1 data: "Treatment") and twoway repeated measures ANOVAs ("Treatment" × "Days" for days 1 to 5 data) followed by Post-hoc Tukey tests. ${ }^{\circledR} P<0.05,{ }^{*} P<0.01,{ }^{\#} P<0.001$, indicate levels of significance relative to the vehicle+amphetamine or vehicle+phencyclidine group. ${ }^{s \$} P<0.05$, indicate significant difference across the 5 test days with eachin group.

hyperlocomotion induced by amphetamine, as there was a significant group difference between the amphetamine and olanzapine group $(P<0.001)$ and between the amphetamine and chlordiazepoxide group $(P=0.006)$. On phencyclidine-induced hyperlocomotion, one-way ANOVA revealed a significant main effect of "Treatment" $\left(F_{(2,20)}=4.111, P=0.034\right)$. Post-hoc Tukey tests showed that in comparison to the vehicle treatment, phencyclidine produced a robust increase in motor activity $(P<0.001)$. Our data also showed that only olanzapine significantly attenuated the acute effect of phencyclidine, as indicated by the finding that only the olanzapine group significantly differed from the phencyclidine group $(P=0.027)$, but the chlordiazepoxide group did not $(P=0.229)$.

3.3.2. Repeated olanzapine, but not chlordiazepoxide treatment attenuated inhibition on amphetamine-induced hyperlocomotion across days, but significantly potentiated inhibition on phencyclidine-induced hyperlocomotion

For amphetamine-induced hyperlocomotion, two-way repeated measures ANOVAs with treatment conditions (e.g. vehicle, olanzapine or chlordiazepoxide) as the between-subjects variable and test days as the within-subjects variable revealed a significant main effect of "Days" $\left(F_{(4,72)}=3.139, P=0.019\right)$ and a significant main effect of "Treatment" $\left(F_{(2,18)}=22.052, P<0.001\right)$, but no significant "Treatment" $\times$ "Days" interaction $\left(F_{(872)}=0.967, P=0.469\right)$. Repeated treatment of olanzapine and chlordiazepoxide significantly inhibited amphet- amine-induced hyperlocomotion throughout five test days (Posthoc Tukey two-group comparisons: olanzapine vs. amphetamine, $P$ $<0.001$, chlordiazepoxide vs. amphetamine, $P<0.001)$. Although the effect of olanzapine persisted throughout the 5 test days, it should be noted that the average inhibition of olanzapine on amphetamineinduced hyperlocomotion decreased from $45.5 \%$ on day 1 to $29.9 \%$ on day 5 (Figure 6E). In contrast, the effect of chlordiazepoxide on amphetamine-induced hyperlocomotion was relatively stable. Twoway repeated measures ANOVA on the data from the chlordiazepoxide rats revealed no significant main effectof "Days" $\left(F_{(4,24)}=0.410\right.$, $P=0.800)$. For the phencyclidine-induced hyperlocomotion, twoway repeated measures ANOVA showed a significant main effect of "Treatment" $\left(F_{(218)}=8.921, P=0.002\right)$, a significant main effect of "Days" $\left(F_{(4.72)}=4.218, P=0.004\right)$, and "Treatment" $\times$ "Days" interaction $\left(F_{(8,72)}=2.958, P=0.006\right)$. Inspection of Figure $6 \mathrm{E}$ and $F$ suggests that repeated treatment of olanzapine potentiated inhibition on phencyclidine-induced hyperlocomotion across the 5 test days as the per cent inhibition changed from $31 \%$ on day 1 to $53 \%$ on day 5 , whereas chlordiazepoxide tended to lose its inhibition (19\% on day 1 , and $9 \%$ on day 5 ).

To better understand the behavioral patterns of all the drugs tested in this study on amphetamine and phencyclidine-induced hyperlocomotion, we summarized the results from all three experiments and used the per cent inhibition on each day as a measure of a drug's efficacy. As can be seen in Figure 6, with repeated treatment, haloperidol, clozapine and olanzapine all gradually lost their ability to inhibit amphetamine-induced hyperlocomotion as there was a steady decrease in \% inhibition, whereas their ability to inhibit phencyclidine-induced hyperlocomotion progressively increased across sessions (Figure 6A-E). In contrast, chlordiazepoxide (Figure $6 \mathrm{~F}$ ) exhibits no impact on phencyclidine-induced hyperlocomotion. Figure 7 shows the per cent inhibition changes from day 1 to day 5 for all antipsychotics tested in this study. On day 1 , haloperidol and olanzapine show a higher efficacy in inhibiting amphetamine-induced hyperlocomotion than phencyclidine-induced one, whereas clozapine shows the opposite effect. Clozapine is more efficacious in inhibiting phencyclidine-induced hyperlocomotion than amphetamine-induced one (Figure 7). However, on day 5, all three drugs had a higher per cent inhibition on phencyclidine-induced hyperlocomotion than on amphetamine-induced hyperlocomotion. This change was due to an increase of per cent inhibition on phencyclidine-induced hyperlocomotion and a decrease of inhibition on amphetamine-induced hyperlocomotion from day 1 to day 5 .

\section{Discussion}

Using two well-established hyperlocomotion models, we examined and compared the effects of repeated antipsychotic treatment on hyperlocomotion induced by repeated amphetamine and phencyclidine treatment in an attempt to develop clinically relevant animal models of antipsychotic drugs that can capture the time course of antipsychotic action, e.g., an early-onset and progressively increased effect over time. Results show that both typical (haloperidol) and atypical (clozapine, olanzapine) antipsychotics acutely inhibited phencyclidine-induced hyperlocomotion and progressively enhanced this inhibitory effect over the repeated treatment period. In contrast, an anxiolytic drug chlordiazepoxide did not show this pattern of action. Repeated chlordiazepoxide treatment gradually attenuated its inhibition on phencyclidine-induced hyperlocomotion. Although antipsychotic drugs also acutely inhibited amphetamine-induced hyperlocomotion, so did chlordiazepoxide, thus it is impossible to distinguish antipsychotics from chloridiazepoxide on the basis of this action. In addition, repeated antipsychotic treatments gradually lost their inhibition on amphetamineinduced hyperlocomotion. Based on these findings, we suggest that the repeated phencyclidine-induced hyperlocomotion model may be better than the repeated amphetamine model in detecting antipsychotic action, capturing the time course of antipsychotic effect and differentiating antipsychotics from anxiolytics. 
A

A Percent inhibition of haloperidol treatment on amphetamineinduced hyperlocomotion

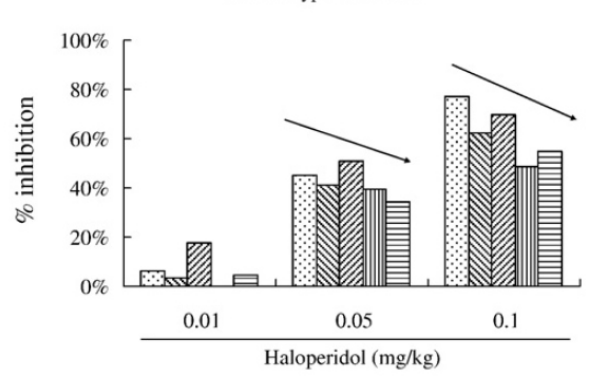

$\mathrm{C}$

Percent inhibition of clozapine treatment on amphetamine-induced hyperlocomotion

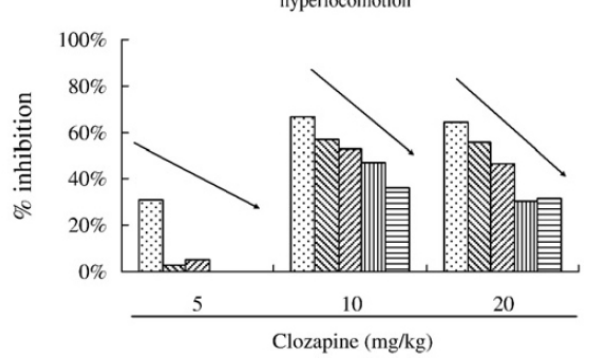

E

E Percent inhibition of olanzapine treatment on amphetamine- or phencyclidine-induced hyperlocomotion

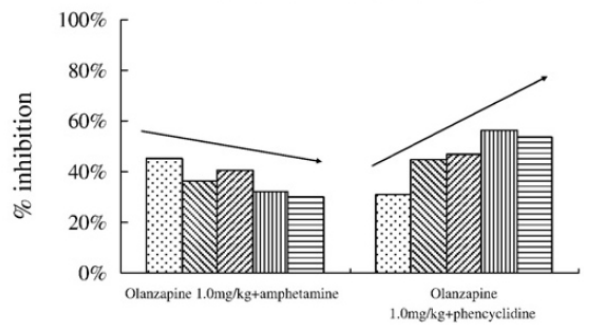

B

Percent inhibition of haloperidol treatment on phencyclidineinduced hyperlocomotion

day1

$\mathbf{D}$ day 2

๑day3

Id day4

$\square$ day 5

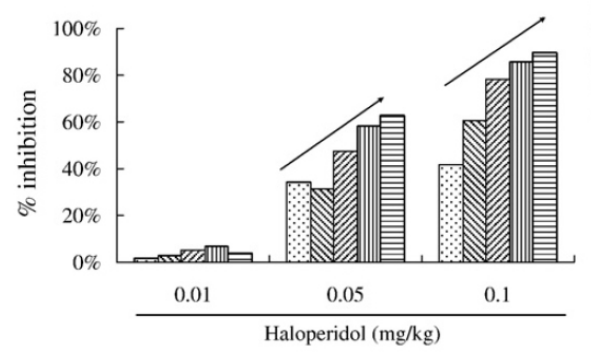

D dayl

\$day2

๑day 3

II day 4

$\square$ day5

D

Percent inhibition of clozapine treatment on phencyclidine-induced hyperlocomotion

Dday1 $\mathbf{D}$ day 2 ๑day 3 凹day4



F Oday1 \$day 2 『day3 凹day4

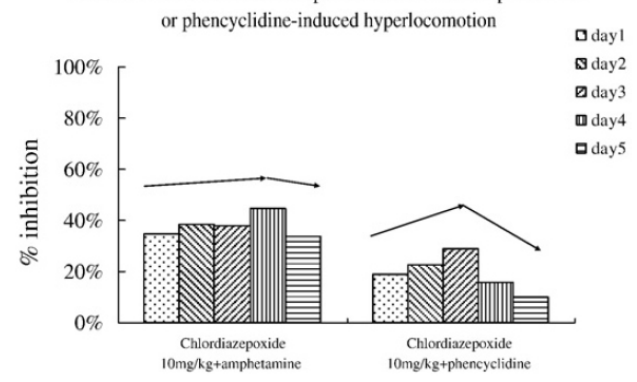

Fig. 6. Percent inhibition of haloperidol ( $0.01,0.05$ or $0.10 \mathrm{mg} / \mathrm{kg}$ ) (A and B), clozapine (5.0,10.0 or $20.0 \mathrm{mg} / \mathrm{kg})(\mathrm{C}$ and D), olanzapine (1.0 mg $/ \mathrm{kg})(\mathrm{E})$ and chlordiazepoxide (10.0 mg $/ \mathrm{kg})$ (F) on hyperlocomotion induced by amphetamine or phencyclidine over the 5 consecutive test days. Percent (\%) inhibition was calculated using this formula: $\%$ inhibition $=1-\frac{\text { Motor activity of one of the drug groups }}{\text { Motor activity of the vehicle + amphetamine group. }}$.

In the majority of antipsychotic drug studies using both hyperlocomotion models, the effects of antipsychotic drugs and other experimental drugs are often tested after a single injection and efforts have been devoted to understanding the neurochemical mechanisms underlying amphetamine and phencyclidine-induced behavioral effects and effects of antipsychotics on both types of hyperlocomotion. All antipsychotics acutely inhibit motor activation effect of amphetamine and phencyclidine (Abekawa et al., 2007; Arnt, 1995; Millan et al., 1999, 2008). Antipsychotics with preferential action on $\mathrm{D}_{2}$ receptors such as haloperidol, fluphenazine, cis(Z)flupentixol, amisulpride, eticlopride, and raclopride all show a preferential inhibitory effect on amphetamine-induced hyperlocomotion over phencyclidine-induced one, whereas atypicals such as clozapine and olanzapine, which are mixed $\mathrm{D}_{2}$-like/5- $\mathrm{HT}_{2 \mathrm{~A}}$ antagonists, have an opposite effect, showing a preferential inhibition on phencyclidineinduced hyperlocomotion (Gleason and Shannon, 1997; MaurelRemy et al., 1995; Millan et al., 1999). Other 5- $\mathrm{HT}_{2 \mathrm{~A}}$ antagonists such as LY53857, ritanserin, ketanserin, fananserin, and MDL100,907, but not $5-\mathrm{HT}_{1 \mathrm{~A}}$ or $5-\mathrm{H}_{\mathrm{T3}}$ antagonists such as WAY 100,635 and zatosetron, also block phencyclidine-induced hyperlocomotion (Gleason and
Shannon, 1997; Millan et al., 1999). Depletion of 5-HT in the nucleus accumbens by parachloroamphetamine abolishes phencyclidineinduced hyperlocomotion (Millan et al., 1999). These findings suggest that inhibition of amphetamine-induced hyperlocomotion is primarily mediated by the antagonistic action on dopamine $\mathrm{D}_{2}$ receptors, whereas inhibition of phencyclidine-induced hyperlocomotion is primarily due to multiple actions of antipsychotics on dopamine $\mathrm{D}_{2}$ and 5-HT receptors, as well as perhaps other molecular sites (Gleason and Shannon, 1997; Maurel-Remy et al., 1995; Millan et al., 1999). Our results are in agreement with these previous reports except that we did not find that acute olanzapine shows a preferential effect on phencyclidine-induced hyperlocomotion (Millan et al., 1999). This discrepancy may be due to methodological differences such as the phencyclidine doses used in these studies. Millan etal. (1999) used 20.0 $\mathrm{mg} / \mathrm{kg}$, whereas we used $3.2 \mathrm{mg} / \mathrm{kg}$. Also, the testing apparatuses were different. Millan et al. (1999) used testing chambers equipped with 2 infrared beams, whereas we used testing boxes equipped with 6 sets of photobeams. Thus, differential effects of typical and atypical antipsychotics on amphetamine or phencyclidine-induced hyperlocomotion might depend on the specific testing conditions. 


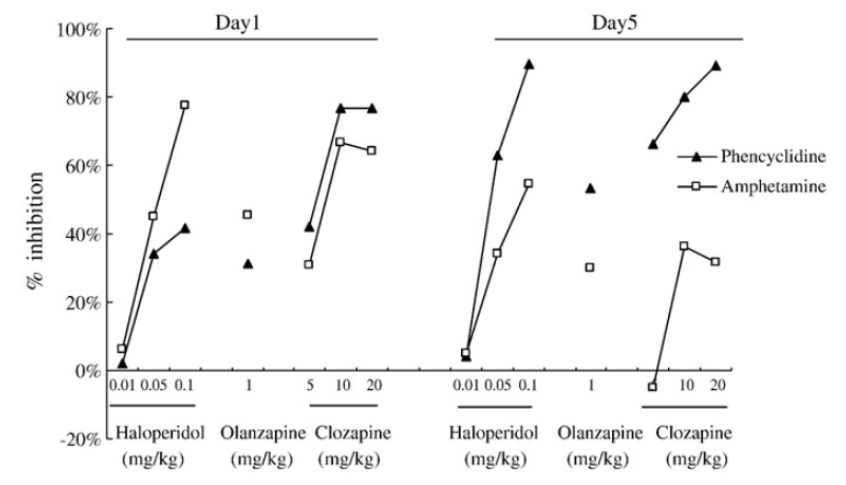

Fig. 7. Relative inhibition efficacy on amphetamine and phencyclidine-induced hyperlocomotion. Percent inhibitions of haloperidol, clozapine or olanzapine treatment on amphetamine or phencyclidine-induced hyperlocomotion on test day 1 and day 5 are plotted together. On day 1 , haloperidol and olanzapine had a higher percent inhibition on amphetamine-induced hyperlocomotion than on phencyclidine-induced hyperlocomotion, and clozapine had a higher percent inhibition on phencyclidineinduced hyperlocomotion than on amphetamine-induced hyperlocomotion. However, on day 5, all three drugs had a higher percent inhibition on phencyclidine-induced hyperlocomotion than on amphetamine-induced hyperlocomotion.

Although acute amphetamine and phencyclidine hyperlocomotion models are useful in delineating the neurobiological mechanisms of action of psychotherapeutic and psychomimetic drugs, they are limited in their ability to capture the intrinsic antipsychotic efficacy of a drug and mimic the time course of antipsychotic treatment in the clinic (Agid et al., 2003; Leucht et al., 2005) because inhibition of amphetamine or phencyclidine-induced hyperlocomotion is not exclusively the property of antipsychotics (Arnt, 1995; Gleason and Shannon, 1997; Millan et al., 1999). In the present study, we employed a repeated treatment schedule for both psychotomimetic drugs and antipsychotic drugs. We found some interesting effects not reported before. First, repeated haloperidol, clozapine, or olanzapine treatment all progressively potentiate inhibition on phencyclidine-induced hyperlocomotion across sessions and prolongs this action within sessions, whereas their inhibition on amphetamineinduced hyperlocomotion is gradually attenuated across sessions and shortened within sessions. Second, repeated chlordiazepoxide treatment retains its inhibition on amphetamine-induced hyperlocomotion, and tends to decrease its inhibition on phencyclidineinduced hyperlocomotion; thus, it shows a behavioral profile distinct from all antipsychotics. Interestingly, antidepressants such as fluoxetine and citalopram also exhibit a behavioral profile distinctive from that of antipsychotics. Acute fluoxetine or citalopram increases amphetamine-induced hyperlocomotion (Fletcher et al., 2006; Millan et al., 2003) but has no effect on phencyclidine-induced model (Redmond et al., 1999). Repeated fluoxetine or citalopram treatment tends to enhance amphetamine-induced hyperlocomotion (Arnt et al., 1984; Sills et al., 1999, 2000) and phencyclidine-induced hyperlocomotion (Redmond et al., 1999). Taken together, a combination of repeated amphetamine and phencyclidine hyperlocomotion models may be utilized to distinguish anxiolytics and antidepressants from antipsychotics.

The present study provides another perspective to evaluate the validity of amphetamine versus phencyclidine model as a model of schizophrenia. Suggestions have been made that phencyclidine model is better than amphetamine model because only NMDA antagonists such as ketamine and phencyclidine can induce neurocognitive deficits and negative symptoms in human and animal subjects resembling those seen in patients with schizophrenia (Javitt and Zukin, 1991; Sams-Dodd, 1998). In contrast, patterns of symptoms induced by amphetamine differ markedly from those seen in schizophrenia (Krystal et al., 2005). In the present study, we found that only the inhibitory effect of repeated antipsychotic treatment on phencyclidine-induced hyperlocomotion mimics the time course of action of antipsychotics in the clinic (e.g. early onset, progressively increasing) (Agid et al., 2003), suggesting that phencyclidine-induced hyperlocomotion may be a valid index of schizophrenia-like psychosis. These results also suggest that repeated phencyclidine-induced hyperlocomotion model based on a repeated antipsychotic treatment regimen is better than amphetamine model in mimicking antipsychotic effcts as seen in the clinic. This point is particularly important for clozapine, as tolerance, rather than a progressively enhanced effect (e.g. sensitization) is often observed with chronic treatment in animals (Goudie et al., 2007a,b). Thus, many researchers have been forced to model this tolerance effect as clozapine's antipsychotic effect in the clinic, which tends to increase over time (Kane et al., 1988; Meltzer et al., 2003). To our best knowledge, inhibition of repeated phencyclidine-induced hyperlocomotion is the only measure that captures the clinical-like pattern of clozapine treatment (e.g. a progressively increased effect); thus, it may reflect the "true" antipsychotic action seen in schizophrenic patients. In this regard, this model is an important addition to the existing animal models based on repeated antipsychotic treatment ( $\mathrm{Li}$ et al., 2007), and thus may serve as a valid model to investigate the neurochemical and neural mechanisms of action of antipsychotic drugs and search for new antipsycotic drugs with novel mechanisms of action.

So then, what mechanism(s) can account for the progressively enhanced inhibition of repeated antipsychotic treatment on phencyclidine-induced hyperlocomotion? The mechanism of action of phencyclidine is complex (Jentsch and Roth, 1999). Besides blocking NMDA receptor channels, phencyclidine can enhance serotonergic, dopaminergic and glutamatergic neurotransmission in the nucleus accumbens and prefrontal cortex (Abekawa et al., 2007; Maurel-Remy et al., 1995; Millan et al., 1999). Based on the findings that acute $5-\mathrm{HT}_{2 \mathrm{~A}}$ antagonists selectively inhibit phencyclidine-induced hyperlocomotion (Gleason and Shannon, 1997), that repeated administration of clozapine attenuates phencyclidineinduced hyperlocomotion even 11 days after the last administration of clozapine (Abekawa et al., 2007) and causes a down-regulation of $5-\mathrm{HT}_{2 \mathrm{~A}}$ receptors in the prefrontal cortex (Doat-Meyerhoefer et al., 2005), as well as the finding that microinjection of phencyclidine into the prefrontal cortex elicits hyperlocomotion (Abekawa et al., 2007), we speculate that antipsychotics may enhance their inhibition on phencyclidine-induced hyperlocomotion by down-regulating 5- $\mathrm{HT}_{2 \mathrm{~A}}$ receptors and concomitantly decreasing phencyclidineinduced dopamine and 5-HT increases in the prefrontal cortex. On the other hand, because repeated phencyclidine treatment can also induce neurotoxic effects consisting of vacuole formation in pyramidal neurons in several corticolimbic brain regions including the posterior cingulate and retrosplenial cortices (Ellison, 1994; Ellison and Switzer, 1993; Olney et al., 1989, 1999), and antipsychotic drugs such as haloperidol, clozapine and olanzapine can effectively block the neurotoxic action of phencyclidine or MK-801 (Farber et al., 1996, 1993; Olney and Farber, 1995) and significantly attenuate sensitization elicited by phencyclidine (Phillips et al., 2001), thus, one cannot exclude the possibility that repeated antipsychotic treatment may enhance its inhibition on phencyclidine-induced hyperlocomotion by progressively improving its efficacy on prevention of vacuole formation in pyramidal neurons in the corticolimbic regions. This issue needs further investigation, and the outcome of this line of research may shed light on the pathophysiology of schizophrenia and the molecular mechanisms responsible for antipsycotic action.

\section{Acknowledgements}

This study was funded in part by a support from the Nebraska Tobacco Settlement Biomedical Research Development Funds, and by a research grant (07R1775) from the Stanley Medical Research Institute to ML and GH. We thank Mr. Wei He for help on Experiment 1. We thank the two anonymous reviewers for their insightful comments. 


\section{References}

Abekawa, T., Ito, K., Koyama, T., 2007. Different effects of a single and repeated administration of clozapine on phencyclidine-induced hyperlocomotion and glutamate releases in the rat medial prefrontal cortex at short- and long-term withdrawal from this antipsychotic. Naunyn Schmiedebergs Arch. Pharmacol. 375 261-271.

Agid, O., Kapur, S., Arenovich, T., Zipursky, R. B., 2003. Delayed-onset hypothesis of antipsychotic action: a hypothesis tested and rejected. Arch. Gen. Psychiatry $60,1,228-1,235$

Agid, O., Seeman, P., Kapur, S., 2006. The "delayed onset" of antipsychotic actionan idea whose time has come and gone. I. Psychiatry Neurosci. 31, 93-100.

Andersen, M. P., Pouzet, B., 2001. Effects of acute versus chronic treatment with typical or atypical antipsychotics on d-amphetamine-induced sensorimotor gating deficits in rats. Psychopharmacology (Berl.) 156, 291-304.

Arnt, J., 1982. Pharmacological specificity of conditioned avoidance response inhibition in rats: inhibition by neuroleptics and correlation to dopamine receptor blockade. Acta Pharm. Toxicol. (Copenh.) 51, 321-329.

Arnt, J., 1995. Differential effects of classical and newer antipsychotics on the hypermotility induced by two dose levels of D-amphetamine. Eur. J. Pharmacol. 283, 55-62.

Arnt, J., Hyttel, J., Overo, K. F., 1984. Prolonged treatment with the specific 5-HTuptake inhibitor citalopram: effect on dopaminergic and serotonergic functions. Pol. J. Pharmacol. Pharm. 36, 221-230.

Burghardt, N. S., Sullivan, G. M., McEwen, B. S., Gorman, J. M., LeDoux, J. E., 2004 The selective serotonin reuptake inhibitor citalopram increases fear after acute treatment but reduces fear with chronic treatment: a comparison with tianeptine. Biol. Psychiatry 55, 1,171-1,178

Doat-Meyerhoefer, M. M., Hard, R., Winter, J. C., Rabin, R. A., 2005. Effects of clozapine and 2,5-dimethoxy-4-methylamphetamine [DOM] on 5- $\mathrm{HT}_{2 \mathrm{~A}}$ receptor expression in discrete brain areas. Pharmacol. Biochem. Behav. 81, 750-757.

Ellenbroek, B. A., Peeters, B. W., Honig, W. M., Cools, A. R., 1987. The paw test: a behavioural paradigm for differentiating between classical and atypical neuroleptic drugs. Psychopharmacology (Berl.) 93, 343-348.

Ellison, G., 1994. Competitive and non-competitive NMDA antagonists induce similar limbic degeneration. Neuroreport 5, 2,688-2,692.

Ellison, G., Switzer III, R. C., 1993. Dissimilar patterns of degeneration in brain following four different addictive stimulants. Neuroreport 5, 17-20.

Emsley, R., Rabinowitz, J., Medori, R., 2006. Time course for antipsychotic treatmen response in first-episode schizophrenia. Am. J. Psychiatry 163, 743-745.

Farber, N. B., Price, M. T., Labruyere, J., Nemnich, J., St. Peter, H., Wozniak, D. F. Olney, J. W., 1993. Antipsychotic drugs block phencyclidine receptor-mediated neurotoxicity. Biol. Psychiatry 34, 119-121.

Farber, N. B., Foster, J., Duhan, N. L., Olney, J. W., 1996. Olanzapine and fluperlapine mimic clozapine in preventing MK-801 neurotoxicity. Schizophr. Res. 21, 33-37.

Fletcher, P. J., Sinyard, J., Higgins, G. A., 2006. The effects of the 5-HT ${ }_{(2 \mathrm{C})}$ receptor antagonist SB242084 on locomotor activity induced by selective, or mixed, in direct serotonergic and dopaminergic agonists. Psychopharmacology (Berl.) 187, 515-525.

Gelder, M. G., LópezIbor, J. J., Andreasen, N. C., 2000. New Oxford Textbook of Psychiatry. Oxford University Press, Oxford, p. 2.v. (xxvii, 2,131).Gleason, S. D., Shannon, H. E., 1997. Blockade of phencyclidine-induced hyperlocomotion by olanzapine, clozapine and serotonin receptor subtype selective antagonists in mice. Psychopharmacology (Berl.) 129, 79-84.

Glick, I. D., Shkedy, Z., Schreiner, A., 2006. Differential early onset of therapeutic response with risperidone vs. conventional antipsychotics in patients with chronic schizophrenia. Int. Clin. Psychopharmacol. 21, 261-266.

Goudie, A. J., Cole, J. C., Sumnall, H. R., 2007a. Olanzapine and JL13 induce cross-tolerance to the clozapine discriminative stimulus in rats. Behav. Pharmacol. 18, 9-17.

Goudie, A. J., Cooper, G. D., Cole, J. C., Sumnall, H. R., 2007b. Cyproheptadine resembles clozapine in vivo following both acute and chronic administration in rats. J. Psychopharmacol. 21, 179-190.

Grace, A. A., Bunney, B. S., 1986. Induction of depolarization block in midbrain dopamine neurons by repeated administration of haloperidol: analysis using in vivo intracellular recording. J. Pharmacol. Exp. Ther. 238, 1092-1100.

Hoffman, D. C., Donovan, H., 1995. Catalepsy as a rodent model for detecting antipsychotic drugs with extrapyramidal side effect liability. Psychopharmacology (Berl.) 120, 128-133.

Javitt, D. C., Zukin, S. R., 1991. Recent advances in the phencyclidine model of schizophrenia. Am. J. Psychiatry 148, 1,301-1,308.

Jentsch, J. D., Roth, R. H., 1999. The neuropsychopharmacology of phencyclidine: from NMDA receptor hypofunction to the dopamine hypothesis of schizophrenia. Neuropsychopharmacology 20, 201-225.

Joordens, R. J., Hijzen, T. H., Olivier, B., 1998. The anxiolytic effect on the fear-potentiated startle is not due to a non-specific disruption. Life Sci. 63, 2,227-2,232.

Kalinichev, M., Robbins, M. J., Hartfield, E. M., Maycox, P. R., Moore, S. H., Savage, K. M., Austin, N. E., Jones, D. N., 2008. Comparison between intraperitoneal and subcutaneous phencyclidine administration in Sprague-Dawley rats: a locomotor activity and gene induction study. Prog. Neuropsychopharmacol. Biol. Psychiatry 32, 414-422.

Kane, J., Honigfeld, G., Singer, J., Meltzer, H., 1988. Clozapine for the treatmentresistant schizophrenic. A double-blind comparison with chlorpromazine. Arch Gen. Psychiatry 45,789-796.

Kapur, S., VanderSpek, S. C., Brownlee, B. A., Nobrega, J., 2003a. Antipsychotic dosing in preclinical models is often unrepresentative of the clinical condition: a suggested solution based on in vivo occupancy. J. Pharmacol. Exp. Ther. 305, 1-7.

Kapur, S., VanderSpek, S. C., Brownlee, B. A., Nobrega, J. N., 2003b. Antipsychoti dosing in preclinical models is often unrepresentative of the clinical condition: a suggested solution based on in vivo occupancy. J. Pharmacol. Exp. Ther.305, 625-631.

Kapur, S., Arenovich, T., Agid, O., Zipursky, R., Lindborg, S., Jones, B., 2005. Evidence for onset of antipsychotic effects within the first 24 hours of treatment. Am. J. Psychiatry 162, 939-946.

Klint, T., 1991. Effects of 8-OH-DPAT and buspirone in a passive avoidance test and in the elevated plus-maze test in rats. Behav. Pharmacol. 2, 481-489.

Krystal, J. H., Perry Jr., E. B., Gueorguieva, R., Belger, A., Madonick, S. H., AbiDargham, A., Cooper, T. B., Macdougall, L., Abi-Saab, W., D'Souza, D. C., 2005. Comparative and interactive human psychopharmacologic effects of ketamine and amphetamine: implications for glutamatergic and dopaminergic model psychoses and cognitive function. Arch. Gen. Psychiatry 62, 985-994.

Leucht, S., Busch, R., Hamann, J., Kissling, W., Kane, J. M., 2005. Early-onset hypothesis of antipsychotic drug action: a hypothesis tested, confirmed and extended. Biol. Psychiatry 57, 1,543-1,549.

Li, M., Parkes, J., Fletcher, P. J., Kapur, S., 2004. Evaluation of the motor initiation hypothesis of APD-induced conditioned avoidance decreases. Pharmacol. Biochem. Behav. 78, 811-819.

Li, M., Fletcher, P. J., Kapur, S., 2007. Time course of the antipsychotic effect and the underlying behavioral mechanisms. Neuropsychopharmacology 32, 263-272.

Maurel-Remy, S., Bervoets, K., Millan, M. J., 1995. Blockade of phencyclidineinduced hyperlocomotion by clozapine and MDL 100,907 in rats reflects antagonism of 5-HT $_{2 \mathrm{~A}}$ receptors. Eur. J. Pharmacol. 280, R9-11.

Mead, A., Li, M., Kapur, S., 2008. Clozapine and olanzapine exhibit an intrinsic anxiolytic property in two conditioned fear paradigms: contrast with haloperidol and chlordiazepoxide. Pharmacol. Biochem. Behav. 90, 551-562.

Meltzer, H. Y., Li, Z., Kaneda, Y., Ichikawa, J., 2003. Serotonin receptors: their key role in drugs to treat schizophrenia. Prog. Neuropsychopharmacol. Biol. Psychiatry 27, 1,159-1,172

Millan, M. J., Brocco, M., Gobert, A., Joly, F., Bervoets, K., Rivet, J., Newman-Tancredi, A., Audinot, V., Maurel, S., 1999. Contrasting mechanisms of action and sensitivity to antipsychotics of phencyclidine versus amphetamine: importance of nucleus accumbens 5-HT sites for PCP-induced locomotion in the rat. Eur. J. Neurosci. 11, 4,419-4,432.

Millan, M. J., Veiga, S., Girardon, S., Brocco, M., 2003. Blockade of serotonin 5-HT and $5-\mathrm{HT}_{2 \mathrm{~A}}$ receptors suppresses the induction of locomotor activity by $5-\mathrm{HT}$ reuptake inhibitors, citalopram and fluvoxamine, in NMRI mice exposed to a novel environment: a comparison to other 5-HT receptor subtypes. Psychopharmacology (Berl.) 168, 397-409.

Millan, M. J., Loiseau, F., Dekeyne, A., Gobert, A., Flik, G., Cremers, T. I., Rivet, J M., Sicard, D., Billiras, R., Brocco, M., 2008. S33138 (N-[4-[2-[(3aS,9bR)-8-cyano1,3a,4,9b-tetrahydro[1] benzopyrano[3,4-c]pyrrol-2(3H)-үl)-ethyl]phenyl-acetamide), a preferential dopamine $D_{3}$ versus $D_{2}$ receptor antagonist and potential antipsychotic agent: III. Actions in models of therapeutic activity and induction of side effects. J. Pharmacol. Exp. Ther. 324, 1,212-1,226.

Natesan, S., Reckless, G. E., Nobrega, J. N., Fletcher, P. J., Kapur, S., 2006. Dissociation between in vivo occupancy and functional antagonism of dopamine $\mathrm{D}_{2}$ receptors: comparing aripiprazole to other antipsychotics in animal models. Neuropsychopharmacology 31, 1,854-1,863.

Olney, J. W., Farber, N. B., 1995. Glutamate receptor dysfunction and schizophrenia. Arch. Gen. Psychiatry 52, 998-1007.

Olney, J. W., Labruyere, J., Price, M. T., 1989. Pathological changes induced in cerebrocortical neurons by phencyclidine and related drugs. Science 244, 1,360-1,362.

Olney, J. W., Newcomer, J. W., Farber, N. B., 1999. NMDA receptor hypofunction model of schizophrenia. J. Psychiatr. Res. 33, 523-533.

Phillips, M., Wang, C., Johnson, K. M., 2001. Pharmacological characterization of locomotor sensitization induced by chronic phencyclidine administration. I. Pharmacol. Exp. Ther. 296, 905-913.

Raedler, T. J., Schreiner, A., Naber, D., Wiedemann, K., 2007. Early onset of treatment effects with oral risperidone. BMC Psychiatry 7, 4 .

Redmond, A. M., Harkin, A., Kelly, J. P., Leonard, B. E., 1999. Effects of acute and chronic antidepressant administration on phencyclidine (PCP) induced locomotor hyperactivity. Eur. Neuropsychopharmacol. 9, 165-170.

Robertson, G. S., Fibiger, H. C., 1992. Neuroleptics increase c-fos expression in the forebrain: contrasting effects of haloperidol and clozapine. Neuroscience 46, 315-328.

Sams- Dodd, F., 1998. A test of the predictive validity of animal models of schizophrenia based on phencyclidine and D-amphetamine. Neuropsychopharmacology $18,293-304$.

Sams-Dodd, F., 1999. Phencyclidine in the social interaction test: an animal model of schizophrenia with face and predictive validity. Rev. Neurosci. 10, 59-90.

Sills, T. L., Greenshaw, A. J., Baker, G. B., Fletcher, P. J., 1999. Acute fluoxetine treatment potentiates amphetamine hyperactivity and amphetamine-induced nucleus accumbens dopamine release: possible pharmacokinetic interaction. Psychopharmacology (Berl.) 141, 421-427.

Sills, T. L., Greenshaw, A. J., Baker, G. B., Fletcher, P. J., 2000. Subchronic fluoxetine treatment induces a transient potentiation of amphetamine-induced hyperlocomotion: possible pharmacokinetic interaction. Behav. Pharmacol. 11, 109-116.

Swerdlow, N. R., Braff, D. L., Geyer, M. A., 2000. Animal models of deficient sensorimotor gating: what we know, what we think we know, and what we hope to know soon. Behav. Pharmacol. 11, 185-204.

Weiner, I., 2003. The "two-headed" latent inhibition model of schizophrenia: modeling positive and negative symptoms and their treatment. Psychopharmacology (Berl.) 169, 257-297. 